\title{
As políticas que incidem sobre a vida
}

\section{Policies that focus on life}

\section{Leila Domingues Machado*}

Professora do Departamento de Psicologia e do Programa de Pós-Graduação em Psicologia Institucional da Universidade Federal do Espírito Santo - UFES, Vitória, ES, Brasil

\section{Maria Cristina Campello Lavrador**}

Professora do Departamento de Psicologia e do Programa de Pós-Graduação em Psicologia Institucional da Universidade Federal do Espírito Santo - UFES, Vitória, ES, Brasil

\begin{abstract}
RESUMO
Trata-se de discussão acerca das políticas que incidem, no contemporâneo, sobre a vida, mais especificamente, sobre os modos de subjetivação, a partir da obra de Michel Foucault. Nomeamos poder a uma correlação de forças que se faz por combates, por enfrentamentos, por lutas. Nesse sentido, o poder não é algo exterior que vem incidir sobre nós. Esta imanência do poder nos solicita sempre análises do que estamos colocando em funcionamento: estratégias de dominação e estratégias de resistência. A resistência é o limite permanente do poder ou seu ponto de inversão. Desta forma, pode-se pensar que as políticas que incidem sobre a vida abarcam tanto dispositivos de poder quanto exercícios de resistências. Tensão que se faz na gestão cotidiana de cada uma de nossas vidas. Assim, coloca-se uma necessidade incessante de avaliarmos o quanto se contribui para a mortificação ou para a expansão da vida.
\end{abstract}

Palavras-chave: Ética, Subjetividade, Poder, Resistência, Biopolíticas.

\section{ABSTRACT}

This is the discussion about the policies dealing in contemporary, about life, more specifically, on the modes of subjectivity, from the work of Michel Foucault. We name power as a correlation of forces that is by fighting, by confrontation. Accordingly, the power is not something outside that is focused on us. This immanence of power in the analysis of the calls when we are putting into operation: strategies of domination and strategies of resistance. The resistance is the limit of the permanent or the point of reversal. Thus, one can think that the policies that affect the life span of both devices as power of resistance exercises. Tension that is present in the daily management of each life. Thus, there is an incessant need to assess how it contributes to the mortification or the expansion of life.

Keywords: Ethics, Subjectivity, Power, Strength, Bio-politics. 
Os textos de Félix Guattari, solo ou acompanhados de Gilles Deleuze, sempre foram portadores de uma vidência. O termo vidência é aqui utilizado no sentido presente no trecho:

\begin{abstract}
[...] se nossos esquemas sensório-motores se bloqueiam ou se quebram, então pode aparecer outro tipo de imagem: uma imagem óptico-sonora pura, a imagem inteira e sem metáfora, que faz surgir a coisa em si mesma, literalmente, em seu excesso de horror ou de beleza, em seu caráter radical ou injustificável, pois ela não tem mais de ser 'justificada', como bem ou como mal. (DELEUZE, 1990, p. 31)
\end{abstract}

Poderíamos chamar de uma perspicácia sensível que faz com que questões de uma época, que ainda se anunciam, ganhem visibilidade e dizibilidade em alguns textos. Como, por exemplo, no trecho a seguir quando afirma que o que "permitirá a cada um assumir plenamente sua potencialidade processual e fazer, talvez, com que esse planeta, hoje vivido como um inferno por quatro quintos de sua população, transforme-se num universo de encantamentos criadores" (GUATTARI, 1993, p.188). Propomo-nos a transformar essa afirmação de Guattari em questão disparadora para a escrita desse artigo: o que permitirá a cada um assumir plenamente sua potencialidade processual?

O autor nos sugere a necessidade de uma reapropriação existencial (GUATTARI, 1993, p.191) que nos impulsione a desejar que nossas palavras, nossos olhares, nossas vidas sejam diferentes do que são. Diferentes no sentido de menos capturadas, menos servis, menos coadunadas aos padrões, menos reprodutoras de esquemas sutis e cotidianos de micro-fascismos, menos apaixonadas pelo poder, pelos títulos, pelos cargos, pela produtividade acadêmica, pela produção de discípulos. Que políticas de subjetivação temos posto em funcionamento em nossas práticas de produção de conhecimento, ou seja, em nossas práticas acadêmicas? Como temos lidado com essa “[...] imensa extensão dos campos de investigação técnico-científicos e estéticos evoluindo num contexto moral de insipidez e desencanto"? (GUATTARI, 1993, p.177).

Temos trabalhado sob a perspectiva de políticas de subjetivação como processos contínuos de produção de modos de vida, que tanto podem estar referidos à potência quanto à mortificação da vida humana em sua integralidade. Política e subjetivação se entrelaçaram. Todas as políticas que se encontram em curso no campo social produzem e ressoam, ao mesmo tempo, processos de subjetivação.

Vamos explicitar abaixo o que entendemos por políticas de subjetivação, para tanto vamos utilizar pontualmente alguns conceitos, como: singularidade, imanência, ética, liberdade que 
contribuam com o entendimento do que chamamos políticas de subjetivação.

Antonio Negri (1996), em uma entrevista sobre a questão da política no pensamento de Deleuze, afirma:

[...] hoje é impossível definir o político senão como a forma em que a integralidade da vida humana se dá. [...] política não é nem mais e nem menos do que processos de subjetivação, como processos globais e coletivos. [...] O político é o momento mais alto da ética. O político em Deleuze é a capacidade de afirmar a singularidade como absoluta. (p.13)

Podemos dizer que a singularidade é primeira, é pura imanência, indeterminação de "uma vida", de singularidades que nos atravessam e não determinação de um indivíduo que, entretanto, a um só tempo não pode ser confundido com qualquer outro.

Por isso liberar a singularidade - como uma potência impessoal e anônima que não se confunde com o eu consciente de si mesmo que é um efeito e não um disparador do processo pelo qual os fluxos se agenciam - de um padrão que a achata e a aprisiona pode ser entendida como uma política de "encantamentos criadores" que escapa à insipidez.

Uma política que afirma a singularidade como força de existir, que forja e expressa, ao mesmo tempo, modos de vida libertos das amarras dos interesses de um Eu e de um dever moral que transcende à vida. "A imagem do pensamento em Deleuze é já um atuar, dado que justamente não existem estas mediações platônicas ideais e representativas entre ação e pensar" (NEGRI,1996, p.12).

Foucault enfatiza a noção de liberdade como condição e objeto da ética ao afirmar que "a liberdade é a condição ontológica da ética. Mas a ética é a forma refletida assumida pela liberdade. [...] A liberdade é, portanto, em si mesma política" (2004, p.267 e 270).

Desse modo, entendemos que a política é indissociável do pensamento/ação, da liberdade e da ética. A política afirma a singularidade, forja e expressa, ao mesmo tempo, modos de vida. Estamos falando de um sentido da política que envolve os processos de subjetivação que afirmam a positividade criadora, do devir outro em nós, das intensidades que pedem passagem, das diferenciações que nos constitui. Uma política de criação de si e do mundo, políticas de resistência que afirmam a potência alegre da vida como obra de arte.

Hannah Arendt nos brinda com essa frase 'otimista': “[...] os homens, enquanto puderem agir, estão em condições de fazer o improvável e o incalculável e saibam eles ou não, estão sempre fazendo" (2004, p.44). Como suportaríamos esse mundo, essa vida 
se não o fizéssemos, mesmo quando não percebemos, mesmo quando são minúsculos acontecimentos? Acreditar no improvável e no incalculável, “[...] acreditar nisso como no impossível, no impensável, que, no entanto, só pode ser pensado: 'algo possível, senão sufoco'" (DELEUZE, 1990, p.205).

Cada época suscitará a necessidade vital de invenção de potências de possíveis e essa invenção precisará ser forjada em imanência com um dado contexto histórico. A idéia de contexto histórico, tão recorrente nos trabalhos acadêmicos, entretanto, não pode ser confundida com uma história da origem ou com uma história do passado. Quando se trabalha sob a perspectiva da origem, costuma-se buscar uma "exterioridade" ou uma "anterioridade" explicativa. Recorre-se ao estabelecimento de entidades transcendentes, ou melhor, elege-se algo que ocorreu antes ou que está fora como elemento elucidativo.

A análise da constituição de um campo problemático, como é o caso das políticas que incidem sobre a vida na atualidade, se faz a partir de um contexto que envolve os atravessamentos, os desdobramentos das séries que percorrem essa temática. Nesse sentido, não se trata de uma história do passado antes sempre de uma história do presente mesmo quando por meio dela se reinventa o passado. Talvez, seja importante nos determos um pouco mais sobre a noção de história afirmando que "cada formação histórica vê e faz ver tudo o que pode assim como diz tudo o que pode em função das condições de enunciado e de visibilidade" (DELEUZE, 1988, p.68).

\section{História: condições de enunciação e de visibilidade}

A história ressoa diferentes facetas com que valores, saberes, crenças se efetivam em uma determinada época. Formas de humanidade, de política, de conhecimento, enfim, formas de vida se engendram nesse processo. Os contornos dessas transformações nos assinalam para a impossibilidade de naturalizarmos um momento histórico que se metamorfoseia no embate de forças que, no presente, reverberam variações na subjetividade. Mas, o que chamamos de história? De que tipo de história se trata?

Poderíamos ser tentados a dizer que a história seria um encadeamento de fatos, uma sucessão de fatos distribuídos em uma linha reta e contínua do tempo: passado, depois presente e depois futuro. Partindo de um ponto de origem, seguiríamos acompanhando um fato após outro em direção a um suposto ponto de chegada, determinado e inscrito ao infinito. A história seria definida como um conjunto de fatos verdadeiros que vão sempre se sucedendo e que vão sempre sendo superados. O passado passou, o presente já está passando e o futuro já vai chegar. O passado explica o presente e no futuro se localiza o ponto de chegada previamente determinado. Numa sucessão contínua de fatos, os conceitos despontariam como descobertas de algo já dado, já existente e que ainda não 
conhecíamos. Assim, partindo de um ponto de origem, que transcende a própria história, e em direção a um ponto de chegada, que também a transcenderia, o conhecimento seguiria uma evolução linear, neutra, universal e obstinada pela verdade, pelo seu aperfeiçoamento.

Essa concepção caracteriza uma visão de história asséptica em que deixam de aparecer muitas histórias, muitos nomes, acontecimentos, amores e desamores, acertos, equívocos, errâncias, entretanto tudo isso faz parte da história que envolve a todos nós e que construímos em nosso cotidiano.

A partir de outra perspectiva, seria possível pensar a história como um emaranhado de linhas tortuosas, que vem e que vão, que se misturam, que se tocam e se afastam. Passado, presente e futuro se embaralham. O passado não explica o presente, ele nos mostra aproximações e, sobretudo, diferenças. Não porque evoluímos ou retrocedemos e sim porque sempre ocorrem transformações. "A história não é, portanto, uma duração; é uma multiplicidade de tempos que se embaralham e se envolvem uns nos outros" (FOUCAULT, 2000, p.293).

Uma história sempre localizável, sempre pontual, e que exatamente por isso não pode nunca ser tratada como uma história universal e neutra, generalista e totalizante. A análise histórica só se torna possível a partir das desnaturalizações, ou melhor, a partir do momento em que todo um contexto sócio-histórico-político-culturaleconômico oferece suporte para a sua compreensão.

Foucault faz uma história das condições - que não são universais em que emergem objetos, sujeitos, conceitos, que variam com a história, com as configurações de determinados dinamismos espaçostemporais, analisando o que é dito, como é dito e porque é dito.

Determinadas condições históricas possibilitam a emergência de certos jogos de saber e de certas relações de poder. Saberes e poderes que se produzem no emaranhado de muitas histórias, que constituem corpos, que incitam paixões, onde se travam lutas, onde há acertos e desacertos, há dúvidas e se ensaiam respostas e onde questões se proliferam.

O conhecimento deixa de ocupar o lugar de verdade-absoluta para assumir a conotação de uma resposta-provisória para as questões que emergem em uma dada época e em um dado lugar. Os conceitos são invenções, são instrumentos de análise, também provisórios e também datáveis. Isto porque o mundo muda, porque as pessoas mudam, porque mudam seus problemas, mudam suas indagações. Como um conceito que permaneceria imutável poderia dar conta das transformações que ocorrem? Pode-se fingir que as mudanças não ocorreram ou pode-se ficar repetindo a mesma explicação para o que já se tornou diverso. 
Compartilhamos da idéia de pensar o presente historicamente, nem antes e nem fora do tempo, com seus limites e possibilidades. Até porque o possível não é o que está dado e sim nossa ousadia de inventar sonhos e torná-los atuais. Isso implica arrancar a história de si mesma para dar visibilidade aos devires, para experimentar a relação com a alteridade, com o mundo, com a vida. Experimentar, neste caso, assume o sentido de um devir outro, percorrido por "uma névoa não histórica [...] sem a qual nada se faria na história" (DELEUZE; GUATTARI, 1992, p.144), um expresso que está em vias de se fazer, o que não tem começo e nem fim, mas que se faz no 'entre', que não é oposição e nem complementaridade de dois opostos, mas diferença entre duas coisas distintas. História e experimentação são distintas uma da outra, porém são indissociáveis. A história aponta para as condições pelas quais emergem as experimentações que, por sua vez, fogem, desviam da própria história. Pode-se dizer que uma depende da outra, ou melhor, é a história que torna a experimentação algo vivido, este vivido depende das condições históricas que, por sua vez, dependem da própria experimentação. "O a-histórico é similar a uma atmosfera que nos envolve e na qual a vida se produz sozinha, para desaparecer uma vez mais com a aniquilação dessa atmosfera" (NIETZSCHE, 2003, p.12).

Como passear na história produzindo desvios e devindo novas possibilidades de existência? História e devir, um duplo que "não é uma reprodução do Mesmo, é uma repetição do Diferente. Não é a emanação de um Eu, é a instauração da imanência de um sempreoutro ou de um Não-eu" (DELEUZE, 1988, p.105). Um dobrar a própria história. Então, pode-se dizer, ao mesmo tempo, que o devir não é histórico, mas que só pode ser pensado na história, senão permaneceria indeterminado. Em outras palavras, o devir irrompe e é atualizado na história, mas a desloca ao agir pelo 'meio' e com isso escapa à história, aquela capaz de captá-lo em seu estado vivido.

O "devir" não é história; hoje ainda a história designa somente o conjunto das condições, por mais recentes que sejam, das quais nos desviamos para um devir, isto é, para criarmos algo de novo. (DELEUZE; GUATTARI, 1992, p.125)

Uma história do presente, no sentido de uma atualidade, que não se volta ao passado para pensar o presente, mas para delimitar a diferença dos modos de existência em determinadas formações históricas. O que levou a cada coisa? Quais devires? Que movimentos? Quais condições?

O que interessa a Foucault é a nossa atualidade, "como" e "o que" temos conseguido ver, dizer, sentir, pensar, pois a forma como conjugamos esses verbos constitui nossos modos de existência. 
Trata-se sempre de uma história do que se passa entre o que estamos deixando de ser e o que vamos nos tornando.

Ressoar da luta constante entre as forças. Tensão que marca as relações de poder e as linhas de resistência. Poder sobre a vida e potência de vida. Os conceitos de poder, de biopoder e de resistência, propostos por Foucault, mostram-se fundamentais para pensarmos sobre políticas de subjetivação. Dito de outra forma, para pensarmos as correlações de força, os jogos de poder e saber que constituem os processos de subjetivação ou que criam modos de vida.

\section{Poder e vida}

Uma situação estratégica complexa nomeada poder, que não coincide com algo que se possua ou que se doe, nem que se troque ou que se adquira, nem que se retome ou que se perca ou que se guarde. Enfim, o poder não se refere à propriedade e nem a algo substancializado. É poder sem rei, é poder anônimo ou estratégias sem sujeito, que geram, entretanto, um emaranhado de políticas de subjetivação. Poderíamos dizer até que o poder em 'si mesmo' não é nada: o poder funciona. Misturando-se a Nietzsche, Foucault afirma que nomeamos 'poder' às correlações de forças que se fazem por combates, por enfrentamentos, por lutas. Assim, o poder deve sempre ser pensado como relações de poder.

Por ser relações de forças, o poder não tem forma e nem é uma relação entre formas. A relação de forças se faz por afetos, por 'estados de poder' locais, mas não localizáveis, por serem móveis, difusos e instáveis. Pelo poder de afetar e de ser afetado, por afetos ativos (suscitar, incitar etc.) e afetos reativos (ser incitado, ser suscitado) presentes em cada força. "O poder de ser afetado é como uma matéria da força, e o poder de afetar é como uma função da força" (DELEUZE, 1988, p.79). Embora essa 'matéria' e essa 'função' não tenham ainda uma forma. Somente quando as relações de força se atualizam, quando se encarnam, é que assumem formas, percorrendo todo o campo social nas formas do dizer e nas formas do ver. O poder não vê e não fala, mas faz ver e falar.

Enquanto o poder é relação de forças, é exercício, o saber é relação de formas, é regulamento. Entre ambos há heterogeneidades, pressuposições entrecruzadas, capturas recíprocas e imanência mútua. O poder envolve matérias não formadas e funções não formalizadas, enquanto o saber envolve funções formalizadas e matérias formadas. As relações de forças desestabilizam as formas, alteram suas direções e contornos. Enquanto os saberes conferem formas às relações de forças.

Pensar o poder como anônimo ou como estratégias sem sujeito não se refere a uma ausência de pessoas, grupos ou instituições envolvidas nesse exercício. $O$ anonimato se refere a um deslocamento da questão 'quem tem o poder?' para 'como um poder 
se exerce?'. Quem tem o poder seria antes uma questão labiríntica. Isso porque o poder é onipresente e ao mesmo tempo um não lugar fixo ou central. Está em tudo e em toda parte, se produz a cada instante, no entanto, não engloba tudo sob uma invencível unidade. A resistência é primeira. Ela não é poder, nem contra-poder, nem recusa. É mais uma permanente insistência. Sendo assim, o poder 'não é tudo' embora precise nos fazer continuamente crer em sua onipotência.

[...] começar a análise pelo 'como' é introduzir a suspeita de que o 'poder' não existe; é perguntar, em todo caso, a que conteúdos significativos podemos visar quando usamos este termo majestoso, globalizante e substantificador; é desconfiar que deixamos escapar um conjunto de realidades bastante complexo, quando engatinhamos indefinidamente diante da dupla interrogação: 'O que é o poder?' 'De onde vem o poder?' (FOUCAULT, 1995, p.240)

Não importa tanto 'quem' e sim 'o que faz funcionar', isso porque o 'quem' é contingente ou numa dada situação poderia ser qualquer um de nós. "Todos nós temos fascismo na cabeça; e mais fundamentalmente ainda: todos nós temos poder no corpo". Tal deslocamento traz à cena a pertinência da análise de nossas diversas práticas, de quais regimes elas instauram. Parece-nos mais familiar eleger vilões, entretanto, é preciso pensar sobre o poder como algo que se exerce, que circula e forma redes, algo que cria e transita pelo que criou, colocando em xeque os maniqueísmos.

$E$ se nos apaixonamos pelo poder é porque ele funciona escamoteando sua face intolerável. Trata-se de sedução. Quanto mais acreditamos dominar e controlar, mais nos deixamos capturar por dispositivos de dominação e controle. O desejo de ser dominado ou a suposta aquiescência ao domínio ou a servidão seria a dupla face do desejo de dominar. Em outras palavras, quanto mais desejamos controlar mais estamos submetidos ao poder do controle, mais o reverenciamos.

Imanência do poder que solicita sempre análises do que fazemos funcionar por diferentes vias, mas que não coincide com transcendentes. O poder não é algo exterior que vem incidir sobre nós. Nem, tampouco, é fixo, imutável ou se exerce de cima para baixo. O poder circula e, assim, torna-se inconcebível pensá-lo como um fenômeno de dominação maciço e homogêneo. Muitas vezes o dizem hegemônico, contudo, há que se ter certo cuidado, pois hegemônico pode significar preponderância, mas, também, pode significar supremacia. As relações de poder sempre irão implicar exercícios de resistência, linhas de fuga, por isso o hegemônico só cabe se for pensado como uma forma provisória e fugaz. Os regimes de dominação funcionam em cadeia, ou melhor, a dominação não é 
de 'um' sobre 'todos', mas de todos sobre todos e cada um. Mesmo que possamos eleger num dado momento certo foco, nos equivocamos ao concebê-lo como central e permanente.

O poder coloca em jogo relações entre indivíduos, entre grupos, e são essas relações de poder que precisam ser analisadas. No entanto, a idéia de relação não deve ser pensada como uma ação direta sobre o outro. "[...] é preciso distinguir as relações de poder como jogos estratégicos entre liberdades [...] e os estados de dominação, que são o que geralmente se chama de poder" (FOUCAULT, 2004, p.285). A violência sim é uma ação direta sobre o outro, sobre seu corpo. Uma situação de violência implica a supremacia de um sobre o outro e não se coloca a possibilidade de escapar. O evento terá um fim, mas ao longo de sua ocorrência haverá a partição entre os que dominam e os que estão subjugados.

O poder, ao contrário, envolve uma ação sobre uma ação. É preciso que entre os indivíduos envolvidos haja um espaço de liberdade, ou melhor, que a ação não se faça sobre um alvo inerte e sim que nessa ação sobre ação se abram campos de resposta, reações, efeitos, invenções. "Mesmo quando a relação de poder é completamente desequilibrada, [...] um poder só pode se exercer sobre o outro à medida que ainda reste a esse último [alguma] possibilidade" (FOUCAULT, 2004, p.277). A coação seria uma forma de relação já saturada ou a interrupção da própria relação. Só há relações de poder onde há possibilidade de resistência. O poder ordena as probabilidades e o eventual, é da ordem do governo (poder de afetar) mais do que do afrontamento.

[...] é um conjunto de ações sobre ações possíveis; ele opera sobre o campo de possibilidade onde se inscreve 0 comportamento dos sujeitos ativos; ele incita, induz, desvia, facilita ou torna mais difícil, amplia ou limita, torna mais ou menos provável; no limite, ele coage ou impede absolutamente, mas é sempre uma maneira de agir sobre um ou vários sujeitos ativos, e o quanto eles agem ou são suscetíveis de agir. (FOUCAULT, 1995, p.243)

Estados de poder - disposições, modos de se estar - localizáveis e instáveis, pois engendrados nas correlações de forças, em seus desequilíbrios. A correlação de forças não é um jogo entre forças mais fortes e forças mais fracas, há diferença, heterogeneidade, instabilidade, mobilidade. Correlação de forças são processos. Quando se configuram distribuições de poder e apropriações de saber é porque ocorreu um corte no processo, uma parada no processo como diriam Deleuze e Guattari (1972, p.9-10). Não em função das forças serem heterogêneas e sim da desigualdade transfigurar-se em coágulos de dominação. E assim os dispositivos de dominação assumem ares de hegemonia, contudo, a dominação pode ser global 
e não totalizadora e estável, ou seja, regimes de dominação estão por toda parte tanto quanto linhas de resistência que instauram deslocamentos, que quebram modelos, que rompem unidades.

É preciso estar atento para as formas com que cada um de nós faz funcionar uma estratégia de dominação, através de diversas técnicas e táticas, a tornando global. Duplo condicionamento entre estratégias globais e táticas locais, nenhuma descontinuidade, porém nenhuma homogeneidade. Não se trata de procurar por culpados, mas de indagar como se constituem súditos, ou ainda, como corpos, desejos, pensamentos são capturados. Percorrer os exercícios de poder em suas extremidades, em suas formas mais regionais e locais, em sua capilaridade, lá onde investe instituições, onde forja instrumentos de intervenção. Pois ao mesmo tempo em que se retira de cena a unidade e o centro, também se retira a culpa, os maniqueísmos, os dualismos ontológicos, ou melhor, esses não são fundamentos do poder e sim alguns dos seus possíveis efeitos.

A noção de poder em Foucault (1985; 1999), não se confunde com um modo de sujeição que se faça sob a forma da lei ou de um sistema global e hegemônico de dominação localizado num Estado, num estabelecimento, numa classe, num grupo, num indivíduo ou em qualquer outro ponto. Não se trata do modelo do direito e nem do modelo da soberania. Tais formas regulamentadas são efeitos de conjunto dos diversos mecanismos de poder e de seus instrumentos.

Um regime de dominação se configura por múltiplos mecanismos de poder que vão constituindo formas de Estado, de classe, de individualidade. E ao mesmo tempo em que essas configurações são efeitos desses múltiplos mecanismos também são seus intermediários, ou seja, o poder transita pelo que constitui ou tudo o que constitui também o faz funcionar. Em suma, cada um de nós, em cada um de nossos atos, pode reforçar mais ou menos muitos dispositivos de poder.

Em meados do século XVIII, a população emerge como um problema político, econômico e científico das cidades, enfim, como um problema de poder, criando a necessidade do estabelecimento de uma regularidade através de mecanismos globais de controle. Foucault (1999) nos fala da emergência de um poder de regulamentação que funciona fazendo viver e deixando morrer, nomeado como biopoder. Este não diz respeito a um poder soberano de fazer morrer, nem a um enfrentamento e sim a uma relação pautada no biológico. O que significa que a morte assume o sentido de preservação da própria vida. É uma morte que se justifica pela vida. Poderíamos dizer que seria uma espécie de 'fazer morrer para fazer viver' ou 'fazer viver fazendo morrer'.

Deixar morrer ou fazer morrer, esse excesso do biopoder que geri, gera, e também cessa, cansa, priva de vida, faz funcionar muitas formas de morte. Tirar a vida não é somente "o assassínio direto, 
mas também tudo o que pode ser assassínio indireto: o fato de expor à morte ou, pura e simplesmente, a morte política, a expulsão, a rejeição etc" (FOUCAULT, 1999, p.306). Seu alvo é a regulamentação da vida, o controle de seus acidentes, de suas eventualidades, de suas deficiências, ou melhor, de uma partição constante entre o que deve viver e o que pode morrer, entre o que é vida e o que é perigo, o que ameaça a vida. Ao mesmo tempo, todas as biotecnologias visam prolongar a vida, pois o poder tomou posse da vida.

O biopoder somente pôde se constituir em função de uma tecnologia de poder que já se disseminava, ou seja, o poder disciplinar. Estas tecnologias de controle sobre o corpo individual criaram um campo de possibilidade para a emergência de um poder que incide sobre a vida da população.

[...] tecnologia de poder que não exclui a primeira, que não exclui a técnica disciplinar, mas que a embute, que a integra, que a modifica parcialmente e que, sobretudo, vai utiliza-la implantando-se de certo modo nela, e incrustando-se efetivamente graças a essa técnica disciplinar prévia. (FOUCAULT, 1999, p.288-9)

E o maior poderio sobre a vida, ou melhor, a maior eficácia do biopoder ao fabricar modos de vida, se coloca exatamente através da maior naturalização de seus dispositivos. O poder realiza uma eficaz política sobre a vida cada vez que cada um de nós reforça, incita, vigia, majora, organiza, ordena, multiplica, qualifica, mede, avalia, hierarquiza ou faz funcionar uma complexa rede de dispositivos de controle. Há uma proliferação de tecnologias políticas que vão investir todo o espaço-tempo da existência, redundando em diferenciadas políticas de subjetivação.

Contudo, se as tecnologias de poder tem incidido cada vez sobre a vida e sobre as subjetivações, é também por elas que passam as maiores forças de resistência. A vida insiste em escapar continuamente. Quanto mais se é alvo de controle tanto mais podemos acionar em nossas vidas focos de resistências: "as forças que resistiram se apoiaram exatamente naquilo sobre o que ele [poder] investe - isto é, na vida e no homem enquanto ser vivo" (FOUCAULT, 1985, p.186).

Os processos de poder se caracterizam menos por uma potência sem limites e mais por uma ineficácia constitutiva. Pois o poder é cego e produz cegueira, faz ressoar impotências, é onipresente e não onisciente. Por isso a necessidade de produção de tantas tecnologias de dominação e de controle. O poder freqüentemente está em um impasse ou frente a frente com o que lhe escapa.

[...] a resistência vem primeiro, na medida em que as relações de poder se conservam por inteiro no diagrama, 
enquanto as resistências estão necessariamente numa relação direta com o lado de fora, de onde os diagramas vieram. De forma que um campo social mais resiste do que cria estratégias, e o pensamento do lado de fora é um pensamento da resistência. (DELEUZE, 1988, p.96).

Em contrapartida, cada um de nós, em cada uma de nossas práticas cotidianas, pode fazer expandir múltiplas resistências, enfim, criação de ilimitadas linhas de fuga aos regimes de dominação que se configuram em nossos dinamismos espaço-temporais.

Só podemos falar em relações de poder quando são possíveis deslocamentos, limites, escapes, reações imprevisíveis. Entre poder e resistência há uma incitação recíproca e uma provocação permanente. Não se trata de confronto ou de exclusão entre poder e resistência e sim de um jogo complexo: a resistência é condição de existência do poder e seu suporte permanente, enfim, se não há resistência resta apenas a coerção pura e simples da violência $A$ resistência seria o limite permanente do poder ou seu ponto de inversão. Poder e resistências são irredutíveis e, ao mesmo tempo, indissociáveis.

\begin{abstract}
[...] no centro das relações de poder e como condição permanente de sua existência, há uma 'insubmissão' e liberdades essencialmente renitentes, não há relação de poder sem resistência, sem escapatória ou fuga, sem inversão eventual; toda relação de poder implica, então, pelo menos de modo virtual, uma estratégia de luta, sem que para tanto venham a se superpor, a perderem sua especificidade e finalmente a se confundirem. Elas constituem reciprocamente uma espécie de limite permanente, de ponto de inversão possível. [...] Instabilidade, portanto, que faz com que os mesmos processos, os mesmos acontecimentos, as mesmas transformações possam ser decifrados tanto no interior de uma história de lutas quanto na história das relações e dos dispositivos de poder. (FOUCAULT, 1995, p.249)
\end{abstract}

Linhas de resistência, espalhadas por toda a rede de poder, criam imprevisibilidades no que parecia previsível, incertezas no que parecia certo, possibilidades no que parecia impossível, fugas no que estava capturado. Pontos móveis e transitórios, mais ou menos densos, no entanto, seu roçar por corpos e almas criam regiões irredutíveis, pois incitam uma arte de viver.

Por meio de exercícios de resistência cria-se a possibilidade de variações nos modos de vida, pois o padecimento dá lugar à potência de agir. Nesse sentido, resistir não pode coincidir com julgar, negar, culpar, recusar, se opor. Essas são formas assumidas pela intolerância, por micro-fascismos cotidianos e sutis. Essas são formas de dominação impulsionadas pela vontade de verdade. As linhas de 
resistências precisam transmutar recusas, ressentimentos, indisponibilidades, falta de tempo, afirmando a potência criadora e alegre da vida. Isto porque, os exercícios de resistência guardam a força da singularização, são potência de (re)invenção de si.

Foucault é um pensador do duplo, ou melhor, um pensador das multiplicidades. Não há em Foucault proposições de conceitos absolutos ou que funcionem por generalizações. Neste sentido, Foucault busca em Maurice Blanchot $(1987 ; 2001)$ a idéia de Fora, para falar de um pensamento do Fora ou de um pensamento da resistência. Onde a palavra Fora assumiria o sentido de algo mais longínquo que toda exterioridade e, ao mesmo tempo, mais próximo que qualquer interioridade. Um Fora que não nos é exterior e nem tampouco interior. Fora dos diagramas de poder que nos capturam e que ajudamos a difundir. Fora de nossos interesses particulares, de nossas certezas. Fora como abertura à indeterminação, ao inimaginável, ao indizível, ao inumano, ao impensável, ao imprevisível, ao intempestivo, enfim, uma potência dispersa, onde qualquer forma que se ofereça será sempre demasiadamente velha ou nova, demasiadamente estranha ou familiar (FOUCAULT, 1990, p.72). As subjetivações são processos de composição de uma multiplicidade, de forças em devir permanente. Não são o Fora, mas uma Dobra do Fora, uma 'invaginação' do Fora. Também por isso, as subjetivações guardam essa "potência astuciosa de resistência".

"Quando o poder se torna biopoder, a resistência se torna poder da vida, poder-vital [...]" (DELEUZE, 1988, p.99). Desta forma, podemos pensar que as políticas que incidem sobre a vida abarcam tanto dispositivos de biopoder quanto exercício de resistências. Biopolíticas que envolvem poder sobre a vida e potência de vida. Tensão que se faz na gestão cotidiana de cada uma de nossas vidas. Biotecnologias que não respondem somente aos interesses do capital. Necessidade incessante de avaliarmos o quanto trabalhamos para a mortificação ou para a expansão da vida. Necessidade incessante de escolhas que respondam mais a constituição de comuns.

\section{Na cadência dos pêndulos}

Cada um de nós é um espaço-tempo de guerra. E...

[...] essa guerra está presente em todos os verbos freqüentados por esse mim mesmo, como tatear, olhar, ouvir, comer, beber, trabalhar, escrever, dizer, amar, lutar etc. E em cada um deles, com seus problemas próprios e com as questões que os atravessam, há o risco dos desdobramentos do fazer no vasto pêndulo cadenciado pelo liberar e controlar, cadência perturbada a cada emergência das circunstâncias. (ORLANDI, 2002, p.236) 
Como podemos habitar esse espaço-tempo de guerra com menos controle e captura? Como podemos interferir com suavidade na cadência dos pêndulos constituintes da vida? Como tecer a reapropriação existencial que denota um tomar posse da própria vida individual e coletiva?

Guattari mantém um fio de possível quando diz que:

E, no entanto, é possível conceber outras modalidades
de produção subjetiva - estas processuais e
singularizantes. Essas formas alternativas de
reapropriação existencial e de autovalorização podem
tornar-se, amanhã, a razão de viver de coletividades
humanas e de indivíduos que se recusam a entregar-se à
entropia mortífera, característica do período que estamos
atravessando. (GUATTARI, 1993, p.191)

Talvez seja preciso acreditar mais no possível para que possamos criá-lo, para que possamos inventá-lo, para que se processe uma consistência. Deleuze (1998) faz uma distinção entre o possível que se realiza e se estabiliza, e o possível que se cria. 0 primeiro se refere ao possível como realização de um projeto previamente pensável e dado por determinações e limitações. Já o possível que se cria remete a criação de possíveis reais que vêm dos acontecimentos, dos afectos e dos perceptos - afetos e percepções em devir - não nomeáveis a priori, mas que se atualizam na singularização, efetivando a criação de outros possíveis. Essa tensão aponta para o paradoxo "esgotar o possível/criar o possível" (ZOURABICHVILI, 2000, p.335). Esgotar o possível como atualização de um estado de coisa, como apreensão da atualidade de uma situação, para poder criar o possível como potência.

Um duplo, a um só tempo, acreditar na efetuação de "possíveis impossíveis", e desacreditar dos clichês, das idéias prontas, das totalidades, de que tudo já está dado de antemão, de que não temos nada a fazer, nada em que acreditar. Apreender o possível como potência, como criação de novas possibilidades de vida, de novos modos de existência. Acreditar que é possível pensar, agir, sentir diferentemente.

Acreditar na constituição de processos de singularização ou criação de linhas de resistência. Entendendo que singular não se confunde com particular. O particular se refere ao que é próprio, íntimo, idiossincrático. O singular se opõe ao particular, entretanto, não se opõe ao comum. Para Negri (2005) as singularidades são relativas às diferenças, bem como, o comum, assim, o comum e o singular se intercambiam na multidão como um conjunto de singularidades cooperantes. Negri (1988) irá trabalhar a idéia de constituição do comum a partir da noção de comum, como processo de produção 
ontológico, presente na obra inacabada de Deleuze: La Grandeur de Marx. O comum se opõe ao uno, à unidade, à soberania do poder, à concepção de poder hegemônico, ele se refere à própria concepção de comunismo, ao "conceito de comunismo que se constrói no livro inacabado de Deleuze" (NEGRI, 1998, p.41). O comum não é o igual. O comum é feito de diferenças, ao mesmo tempo, é condição das mobilizações produtivas (LAZZARATO, 2007).

Nesse sentido, a concepção de reapropriação existencial se refere à ética, a uma constituição ética de si. Entretanto, essa constituição de si não pode ser egóica, pois isso já faz parte do inferno que vivemos. Trata-se de uma não distinção entre pensamento e ação. Consonância entre os conceitos que utilizo e as práticas que efetivo. Todo conhecimento já faz parte de uma política. Toda política é necessariamente, também, de subjetivação. Tudo isso implica pararmos de 'lavar as mãos', o que significa nos implicamos, de fato, com a constituição de comuns, com a "capacidade de assumir nas próprias mãos as condições biopolíticas da existência" (NEGRI, 2005).

\section{Referências Bibliográficas}

ARENDT, H. O que é política? 5. ed. Rio de Janeiro: Ed. Bertrand Brasil, 2004.

BLANCHOT, M. O espaço literário. Rio de J aneiro: Rocco, 1987.

A conversa infinita. São Paulo: Escuta, 2001.

DELEEUZE, G. Foucault. São Paulo: Editora Brasiliense, 1988. $\overline{1} \overline{9} \overline{9} \overline{0}$.

A imagem-tempo - Cinema 2. São Paulo: Ed. Brasiliense,

DELEUZE, G. ; GUATTARI, F. O Anti-Édipo: capitalismo e esquizofrenia. Lisboa: Assírio \& Alvim, 1972.

O que é a Filosofia? Rio de Janeiro: Editora 34, 1992.

FOUCAULT, M. História da sexualidade I: a vontade de saber. 7.ed. Rio de Janeiro: Graal, 1985.

. O pensamento do exterior. São Paulo: Ed. Princípio, 1990. O sujeito e o poder. In: DREYFUS, H.; RABINOW, P. (Orgs.). Michel Foucault, uma trajetória filosófica: (para além do estruturalismo e da hermenêutica). Rio de Janeiro: Forense Universitária, 1995, p.231-249.

Em defesa da sociedade: curso no Collège de France (1975$\overline{1} \overline{9} \overline{7} \overline{)})$. São Paulo: Martins Fontes, 1999.

Retornar à História. In: Arqueologia das ciências e histórias dos sistemas de pensamento. Rio de Janeiro: Forense Universitária, Coleção Ditos \& Escritos II, 2000, p.282-295.

. A ética do cuidado de si como prática da liberdade. In:

Ética, sexualidade, política. Rio de Janeiro: Forense Universitária, Coleção Ditos \& Escritos V, 2004, p.264-287. 
GUATTARI, F. Da produção de subjetividade. In: PARENTE, A. (Org.). I magem-máquina: a era das tecnologias do virtual. Rio de Janeiro: Editora 34, 1993, p.177-191.

LAZARATO, M. O papel da cultura e da comunicação no capitalismo contemporâneo. Seminário A constituiçãa do comum: cultura e conflitos no capitalismo contemporâneo. Vitória, 21 de maio de 2007.

NEGRI, A. Deleuze y la política: entrevista a Tony Negri. In: ENCUENTROS - Revista de la Catedra de Filosofia Contemporanea, n. 4, p. 09-17, jun. 1996.

El exilio. Barcelona: El Viejo Topo, 1998.

A constituição do comum. II Seminário Internacional Capitalismo Cognitivo: 'Economia do Conhecimento e a Constituição do Comum. Ministério da Cultura, Brasília, 24 de outubro de 2005.2 Disponível em: <http: www.cultura.gov.br/site/2005/10/24/conferencia-aconstituicao-do-comum-antonio-negri/ >. Acesso em: jul.2009. NIETZSCHE, F. Assim falou Zaratustra. Rio de Janeiro: Ed. Civilização Brasileira, 2003.

ORLANDI, L. B. L. Que estamos ajudando a fazer de nós mesmos? In: RAGO, M.; ORLANDI, L. B. L; VEIGA-NETO, A. (Orgs.). I magens de Foucault e Deleuze: ressonâncias nietzschianas. Rio de Janeiro: DP\&A, 2002, p.217-238.

ZOURABICHVILI, F. Deleuze e o possível (sobre o involuntarismo na política). In: ALLIEZ, E. (Org.). Gilles Deleuze: uma vida filosófica. São Paulo: Ed. 34, 2000. p. 333-355.

\section{Endereço para correspondência}

Leila Domingues Machado

UFES, Departamento de Psicologia, Av. Fernando Ferrari, no 514, Campus Universitário Alaor Queiroz de Araújo, Goiabeiras, CEP 29075-910, Vitória - ES, Brasil

Endereço eletrônico: leiladomingues@uol.com.br

Maria Cristina Campello Lavrador

UFES, Departamento de Psicologia, Av. Fernando Ferrari, no 514, Campus Universitário Alaor Queiroz de Araújo, Goiabeiras, CEP 29075-910, Vitória - ES, Brasil

Endereço eletrônico: cristinacampello@uol.com.br

Recebido em: 11/08/2009

Aceito para publicação em: 06/11/2009

Acompanhamento do processo editorial: Deise Mancebo, Marisa Lopes da Rocha e Roberta Romagnoli.

\footnotetext{
Notas

* Doutora em Psicologia Clínica pela PUC-SP

** Doutora em Psicologia pela UFES
} 